\title{
Indicative planning of the innovative development of a federal state in the context of the activation of unforeseen factors of a radical nature (at example of the COVID-19 pandemic)
}

\author{
Tatyana Ladykova ${ }^{1, *}$, Ivan Danilov ${ }^{1}$ \\ ${ }^{1}$ Chuvash State University, 15, Moskovsky prospect, 428015, Cheboksary, Russia
}

\begin{abstract}
The purpose of the article is to identify the main socioeconomic causes and consequences of the COVID-19 coronavirus pandemic in indicative planning of the innovative development of a federal state, as well as the ways to overcome the negative consequences as a new and substantial example of impact of unforeseen factors of a radical nature to a federal state. The main fundamental consequences of the COVID-19 coronavirus pandemic appear to be two interrelated innovation processes (coronavirus' affects): accelerated digitalization of all aspects of socioeconomic activity, as well as socio-economic innovation, namely "zeroing", i.e. gradual displacement of a person from many processes where he is currently carrying out labor activities. In order to overcome the negative consequences of the coronavirus pandemic COVID-19 and other unforeseen factors of a radical nature federal states of the countries and region governments are apt use the tools of innovation and indicative planning.
\end{abstract}

\section{Introduction}

On December 31, 2020, in Wuhan, China, 27 people were hospitalized with pneumonia of unknown origin, 7 of whom were in critical condition. January 9 - it was found that the causative agent of pneumonia is a new type of coronavirus. January 11 - first death from coronavirus. January 20 - First infected with coronavirus in South Korea. January 21 - First infected with coronavirus in the United States. January 22 - Chinese authorities have announced a mutation of the coronavirus and the possibility of a global epidemic. January 23 - the introduction of quarantine in Wuhan. January 24 - Cancellation of all direct flights to Moscow from Wuhan ...

The further explosive spread of the coronavirus, which on February 11, 2020 received its own name COVID-19, led to the WHO's recognition of this process as a pandemic on March 11. On this day, 118 thousand people were affected by this disease. in 114 countries.

This led to the introduction of quarantine or self-isolation regimes in many countries. The borders of almost all countries were closed, for example, in Russia the entry of foreign citizens and stateless persons was prohibited since March 18, on the same day the external

* Corresponding author: ladykova@mail.ru 
borders of the EU were closed. On March 19, a high alert regime was introduced in all Russian regions.

The economies of all countries slowed down, respectively, and the entire world economy plunged into a state of alarming expectations of the real economic consequences of this pandemic. Within the framework of this article, the COVID-19 coronavirus pandemic will be considered as a socio-economic phenomenon, namely, its causes and consequences, which lie mainly in the plane of socio-economic relations.

In the aspect of the problem under study, it is necessary, in our opinion, to formulate answers to several fundamental questions that will allow in the future to implement an effective action plan to minimize negative consequences and not only pandemics.

In this regard, the purpose of the proposed article is to identify the main socio-economic causes and consequences of the COVID-19 coronavirus pandemic, as well as ways to overcome its negative consequences. The decomposition of the research goal led to the formation of the following main tasks: the formulation and verification of a hypothesis about the socio-economic factors that led to the global quarantine, the identification and substantiation of the socio-economic consequences of the pandemic, in particular, the analysis of the sectoral profile, the substantiation of possible options for the development of a particular country in the post-pandemic period. The data for the proposed study were materials of international organizations, publications in Russian and foreign scientific and periodicals, official materials of government agencies.

In the course of the study, the main socio-economic factors that led to the global quarantine, its main consequences and directions for overcoming them were identified. A significant role in these processes of innovation, carried out within the framework of state indicative planning, was identified, and two fundamental consequences in the form of innovation processes were substantiated.

\section{Applied methodology. Literature review}

The data for the proposed research were materials of international organizations, publications in Russian and foreign scientific and periodicals official materials of government agencies.

Due to the fact that at the time of this writing, publications devoted to research on the socio-economic causes and consequences of the COVID-19 coronavirus pandemic have just begun to appear, the authors in a literature review on the subject of the article, based on the logic of the proposed study, considered international rankings in terms of their presence as a threat or pandemic or epidemic challenge and innovation, works that address the role and value of innovation and indicative planning.

The COVID-19 coronavirus pandemic from the point of view of socio-economic processes has shown the vulnerability of humanity and the world economy to negative external factors. Despite all the achievements of scientific and technological progress and medicine, it suddenly turned out that humanity does not have the means (vaccines, drugs, etc.) and health systems that can effectively protect the population from epidemics and pandemics. Europe was divided along the lines of old state borders, and Italy decided to close the country to tourists in 2020. The pandemic also showed the danger of a limited nuclear war, especially in the European theater of operations, the permissibility of which is actively promoted by the US military.

In this regard, it should also be noted that the renowned professor of finance, writer and former Wall Street trader, author of the book "Black Swan. Under the sign of unpredictability "Nassim Taleb back in 2017, in an interview with RBC, called new viruses and bacteria one of the two main threats to humanity. "The media underestimates this danger and rarely makes a fuss about scientific publications that antibiotic resistance in 
bacteria is increasing, or that new strains of viruses are emerging. This neglect turns epidemics into one of the most likely candidates for new "black swans" [1]. At the same time, N. Taleb does not consider the COVID-19 coronavirus a "black swan", because governments and businesses ignored the threat of an epidemic in January 2020, and in April they had to spend billions [2].

The founder of a new approach to the analysis of economic systems was J. Schumpeter [3], who noted in his works that the "norm" of a healthy economy, the main reality of economic theory and practice, is not equilibrium or optimization, but dynamic disequilibrium caused by the activity of an innovator-entrepreneur. Supporting J. Schempeter, P. Drucker believed that innovators "consider changes to be normal and even favorable ... they seek them out, react to them and use them as a source of success" $[4,5]$. Prigogine I.R. the theory of self-organization of non-equilibrium systems was substantiated, incl. and socio-economic, where imbalance can be created as a result of innovation [6], which was later developed by Jansen F. [7].

With regard to the requirements of the 4th industrial revolution, in the direction of which the world economy was moving ahead of the COVID-19 pandemic, it was noted that those countries that will have advanced digital platforms and innovative ecosystems will have an advantage; form a diversified economy, corresponding to the main directions of the 4th industrial revolution; minimize the negative consequences of mass layoffs of workers and increasing social inequality; preserve or optimally transform the basic values of human existence [8]. In this aspect, it can be noted that the pandemic stimulated the world economy to move more rapidly towards meeting the requirements of the 4th industrial revolution, due to the fact that a large number of economic entities actively using digital technologies gained an advantage or minimized the negative consequences of the pandemic and global quarantine.

There are several international rankings that take into account the innovation factor to some extent. Among them, the following main ones can be distinguished: "Doing Business" of the World Bank [9], "The Global Innovation Index" created as a result of cooperation between Cornell University (USA), the European Institute of Business Administration (INSEAD), the World Intellectual Property Organization [10], " Global Competitiveness Index "of the World Economic Forum [11]. In Russia, the "Strategy for the innovative development of the Russian Federation for the period up to 2020" [12], as well as the Strategy for the scientific and technological development of the Russian Federation [13], were developed and adopted.

In light of the COVID-19 coronavirus pandemic, the name of The Global Innovation Index 2019 seems to be prophetic, which was defined as "Shaping a Healthy Lifestyle - The Future of Medical Innovation." At the same time, the following main groups were referred to as promising medical innovations in this document.

First, new scientific breakthroughs, treatments and drugs - genetics and stem cells (cell analysis, gene and stem cell therapy, genetic engineering and editing, including CRISPR technology); nanotechnology (swallowed small devices); biology (development and production of complex biological products); brain research, neurology and neurosurgery (characteristics of the main parts of the brain, new methods of treating mental disorders, treatment of migraines); a new generation of vaccines and immunotherapy (HIV vaccine and universal influenza vaccine, cancer vaccines, immunotherapy, new methods of delivering vaccines inside the body); pain relief (effective, non-addictive pain relievers); maintenance of mental health (pre-symptomatic diagnosis and treatment of Alzheimer's disease and other similar diseases).

Second, new medical technologies - medical devices (3D printers, cardiac devices, implants and bionic devices); medical imaging and diagnostics (high-definition optical imaging and virtual anatomical models, biosensors and markers, 4D human models and 
virtual reality, screening for diseases); precise and personalized medicine (computerassisted surgery, surgical robots, personalized medicine); regenerative medicine (tissue engineering, efficient bio-artificial pancreas).

Third, the organization and technology of innovation - new approaches to research in healthcare (software-based modeling to accelerate research, the use of artificial intelligence in research and clinical trials); new types of healthcare (telemedicine, unmanned drug delivery, remote control and diagnostics, data sharing) [10].

It was noted that innovation brings not only opportunities, but also new risks and will require the transformation of existing ethics and social values, in particular in the field of genetic engineering. It will also require more active government involvement in the implementation of supervisory activities, as well as risk management in this area. In addition, coordination of activities on an international scale is required. Also, the question was raised about the presence of restrictions in the process of saving human life at any cost, as well as in conditions of increasing life expectancy [10].

Significant results were predicted within 10 years in the prevention of influenza, HIV and many other infectious diseases through the development of innovative vaccination strategies. Nowadays, a new influenza vaccine needs to be produced every year to protect against the rapidly mutating influenza virus. Despite all efforts, the vaccine is not always optimal and, on average, in the United States alone, influenza kills nearly 50,000 people per year and causes more than US \$ 87 billion in damage.

Significant resources are currently being devoted to the development of a "universal" influenza vaccine designed to target mutation-resistant portions of the influenza virus, which can provide long-term protection against a wide range of viruses and their strains. In addition, a vaccine like this could reduce the need for annual flu shots, prepare humankind for the next global pandemic and potentially save millions of people. At the time of the release of this report, clinical trials of the first version of such vaccines were carried out in humans [10].

The latest version of Doing Business was released on May 1, 2019. It notes that effective implementation of innovative ideas requires clear rules for doing and organizing business. Labor market regulation in developed countries is correlated with the innovative activity of workers, due to the fact that stability stimulates them to create innovations. At the same time, the ability of firms to adapt to external shocks is influenced by strict labor regulation by the state. This circumstance also negatively affects the innovative activity of firms. The formation of a database on public procurement should contribute to innovations in the implementation of national projects. When compiling this rating, additional points are awarded to those countries that use a risk-based approach in the regulation of social and environmental problems. At the same time, this approach means increased taxation of more risky activities and vice versa [9]. Thus, it can be seen that the government and state regulation of various parties to activities are considered as external risks for enterprises, but did not take into account global challenges and threats that are beyond the boundaries of specific states.

One of the main directions for assessing the country's competitiveness within the Global Competitiveness Index of the World Economic Forum is the innovation ecosystem, which includes business dynamism - administrative requirements (costs of starting a business, opening a business, solvency recovery rate, regulatory framework on bankruptcy issues); culture of entrepreneurship (attitude to entrepreneurial risk, willingness to delegate authority, growth in the number of innovative companies) and innovation potential, which includes specialization and cooperation (quality and qualifications of the workforce, prevalence of clusters in the economy, availability of patents with foreign participants, degree of cooperation in the implementation aspect innovation activity within companies, between companies, between business and scientific institutions); research and 
development (number of scientific publications, number of patents, expenditures on research and development in\% of GDP, places occupied by scientific institutions in international rankings); (the competence of buyers, the number of applications for trademarks per million population) [11].

It was noted that geopolitical tensions are fueling uncertainty that stifles investment and increases supply risks. Disruptions in global supply chains, sudden price hikes, and interruptions in the availability of key resources were predicted as shocks [11]. The shocks noted in this document were realized in 2020 as the consequences of the pandemic and global quarantine.

The COVID-19 coronavirus pandemic can be described as a major challenge, namely a threat that cannot be addressed by simply increasing the resources used. In this strategy, as one of the big challenges, the growth of threats of global pandemics, an increase in the risk of new and return of disappeared infections was noted. At the same time, it is planned to make a transition to personalized medicine, high-tech healthcare and health-preserving technologies, incl. due to the rational use of antibacterial drugs [13].

The World Health Organization advocates for the integration of health and well-being into urban planning is an important step in this direction, including in decision-making on water and sanitation, transport, housing, land use, energy and waste management [14].

\section{Discussion}

The first question is logically what caused such a reaction in many countries to the COVID19 coronavirus pandemic in China, which resulted in the adoption of strict quarantine measures that negatively affected the economy. What caused this "immune response" of the governments of many countries?

From the point of view of the course of socio-economic processes in modern conditions, let us put forward the following hypothesis.

First, the modern world is permeated with many information and digital interconnections. Such innovations as the Internet, social networks, the blogosphere, etc. allow each person to receive personalized information from anywhere in the world. For example, a resident of Russia, Europe or the United States can obtain information about China and many Chinese cities, despite the existence of a sovereign Internet (Chinese firewall) in this country. Therefore, even the Chinese leadership was unable to completely block information about the presence of serious health problems among its citizens. It can be assumed that analyzing the spread and consequences of the coronavirus COVID-19, as well as information flows, the Chinese government decided to introduce quarantine in Wuhan.

Citizens of many countries could see video and photo reports from the deserted streets of Wuhan, not only on social networks, but also in official media. And that was the first step. But nevertheless, China is geographically far from many countries and therefore residents of other countries hoped that China would cope on its own, although many sources of information focused on such negative consequences of the COVID-19 coronavirus as high mortality among the elderly, as well as the need to connect seriously ill patients to artificial ventilation of the lungs (IVL).

Back in the early 2000s. such an explosive spread of information around the world would be difficult. As a result, it can be assumed that humanity has entered a new innovative phase of development of the information component of its socio-economic system, into the so-called "new information reality".

Many experts substantiate the position that information and hybrid wars are currently being waged in the world. One example is the "Arab Spring", when mass demonstrations of citizens took place in a number of Arab countries, the coordination of which was carried out 
using social networks. In one of our articles, we investigated the phenomenon of war as a global economic threat immanent to capitalism [15].

In connection with the COVID-19 coronavirus epidemic in China, many foreign structures responsible for conducting an information war against this country have stepped up their actions to strengthen the negative image of the PRC in the eyes of the world community. In addition, a number of Western media at the initial stage focused on the fact that Iran is after China in terms of infection and mortality. Thus, there were two existential opponents of the United States as carriers of the "terrible" disease. It can be assumed that it was planned to justify the introduction of not only economic, but also punitive sanctions against Iran, such as a complete blockade of all borders, and possibly the introduction of quarantine troops under the auspices of the UN and WHO, which would be based on US troops. A similar scenario was implemented in Africa in 2014-2015 during the Ebola epidemic in Guinea, Liberia and Sierra Leone, where 3,000 American soldiers were sent along with volunteers. Considering the negative attitude of a number of countries towards the Russian Federation, a similar scenario cannot be ruled out in relation to our country under certain conditions.

Thus, the first factor that led to a sharp "immune response" of the world community to the COVID-19 coronavirus pandemic was the informational interconnection of individuals from different countries, as well as the lack of "immunity" to such events.

The second factor was the rapid, explosive spread of the COVID-19 coronavirus around the world, due to the presence of a developed air connection. Like any phenomenon, it has positive and negative sides. The pandemic under consideration has once again confirmed the potential danger of air transport. With its help, any contagious disease can spread practically all over the world within a short period of time, which happens every year with the flu, incl. and with the SARS virus (2002-2003). Therefore, even if the coronavirus COVID-19 had a short incubation period, it would still literally scatter around the world. It is no coincidence that the largest number of infected people was noted in the so-called transport hubs, in Russia - this is Moscow, in the USA - New York. The short period of time between the first infected and the deaths in China and Europe (France, Italy, Spain), enhanced by the media and the Internet, led the world community into a state of a certain collective panic, which was intensified by the realization that humanity lacks medical supplies (vaccines) to counter this threat.

The third factor was the state of health systems in many countries, incl. and in developed European ones. If the first act of the unfolding pandemic crisis was the introduction of quarantine in Wuhan, then the second was the appearance of patients in Europe, where, for example, in Italy, there was a sharp increase and the inability of the Italian health system to effectively treat such patients. After that, residents and leaders of many countries realized that their health care systems did not differ much for the better from the Italian one, with all the ensuing negative consequences. For example, the UK's National Health Service had approximately 94,000 vacancies in hospitals and utilities. At the same time, even before the COVID-19 coronavirus pandemic, there were risks of an increase in this indicator due to burnout and low employee morale. [16, p.78]

Therefore, in almost all countries, self-isolation and quarantine measures were taken like an avalanche in order to prevent a negative Italian scenario for the development of events. Moreover, a fairly significant part of citizens as voters could ask the heads of state and government about preventive measures that were not taken in time.

Once again, we present the three main causes of the pandemic as a socio-economic phenomenon put forward within the framework of our hypothesis: information openness and interpenetration of the world community, developed air traffic and high mobility of the population, and the state of health systems. Based on this list, it can be assumed that a 
similar situation could potentially arise in the future, because viruses constantly mutate and live in symbiosis with everything that exists on Earth, incl. and with a person.

Thus, the first main conclusion can be formulated as follows. Humanity has consistently, and in many cases systematically, moved towards the emergence of a pandemic of this kind. A similar negative (panic) situation can occur periodically. Therefore, in order to prevent such pandemics in the future, it is necessary to take a number of measures of a planned and sometimes directive nature, incl. and using indicative planning tools both at the level of the entire world community and individual countries.

The second main question that needs to be answered is "What socio-economic consequences will the COVID-19 coronavirus pandemic have in the short and long term, when countries used predominantly isolationist measures?"

The first consequence is the global economic crisis. At the same time, it should be noted that many experts noted the overheating of the US economy, in which sooner or later a recession was about to begin and how the latter could affect other countries. Due to the action of the COVID-19 coronavirus factor, this potency has received its practical embodiment. And in place of the virus, there could be another factor catalyzing the implementation of a negative scenario. In theory, the economic downturn may be smaller in those countries that introduced quarantine later than others and left it earlier than others. In reality, the picture of the recession may be somewhat different after a year or several years.

In accordance with the favorable version of the IMF forecast, the global economy will decline by $3 \%$. At the same time, the COVID-19 coronavirus pandemic is called the Great Self-isolation, which will lead to a decline comparable to the Great Depression of 19291933. XX century At the same time, a decline of $6.1 \%$ is expected in developed countries, and $1.0 \%$ in developing countries. More than 170 countries may experience a decline in per capita income [17].

The structure of the recession has a so-called "anti-globalization" character. This is manifested in the fact that the largest recession values are recorded and will continue to be recorded in such industries and activities that served the movement of people and goods between countries. According to the Ministry of Economic Development of the Russian Federation, as of April 20, 2020, the most affected industries were air transportation, air transport, where large enterprises operate, and tourism, exhibition activities, hotels, entertainment and leisure, public catering, consumer services, culture and sports. non-food retail, dental services, i.e. those enterprises, usually small and medium-sized businesses, that directly contacted individual citizens-clients (B2C), and which were closed due to quarantine, and if they were not closed, then the demand for their services would have decreased several times. At the same time, the economic consequences of the pandemic had an impact on 5.3 million people, 3.3 million of whom were employed in the field of small business. This also applies to 526 thousand enterprises, incl. 176 thousand individual entrepreneurs with hired workers [18]. At the same time, according to Russian Railways, since the beginning of April 2020, export supplies of iron ore, coal, grain, oil cargo, fertilizers have increased [19].

This is the so-called first decay contour. The second circuit includes those indirectly affected, for example, airports or large shopping and entertainment centers (B2B). It should be noted here that the list of industries is preliminary and incomplete, since at the time of this writing, there are no reliable statistics for April, the month of complete self-isolation in Russia. Therefore, industries will be considered that have clearly shown a decline or rise during the period of self-isolation.

Suppliers of raw materials can be included in a special group of indirectly affected. During times of such economic downturns, demand and, accordingly, prices for raw materials fall. In this regard, it should be noted that even without the COVID-19 coronavirus pandemic, the demand for fuel and energy resources, especially for oil, was 
below supply and a certain correction of its production was required. This happened before the pandemic began, when the OPEC + countries could not agree on new, reduced quotas for oil production, which led to a sharp decline in the price per barrel. The new agreement reached could no longer affect prices in the face of the raging COVID-19 coronavirus.

The relatively weakly affected industries include retail trade, construction, enterprises that fulfill government orders, the financial sector (large banks, insurance companies, microfinance organizations), agricultural industry, pharmacy chains, etc. The winning industries include a variety of delivery services, IT companies that practiced remote work of employees, a variety of services that provided services for collective remote work, online training, etc.

In this regard, it should also be noted that the industries included in the first group (heavily affected), objectively, cannot expect a quick and complete recovery after the end of the pandemic. At the same time, businesses in the group that benefitted from self-isolation and quarantine could potentially take a larger share of consumer spending than before the pandemic. The main beneficiaries of the pandemic are objectively the industries of production and sale of medicines and healthcare-related goods.

The third main question is "What to do?" It is difficult to answer this question in the short term, because no detailed information. In the long term, several main conclusions can be formulated that were relevant even before the COVID-19 coronavirus pandemic, and after it began, and especially after the self-isolation of all countries, acquired particular significance.

In terms of answering this question, countries have two extreme choices, between which intermediate variants of their combination are placed, determined by the specific characteristics of each country. The first is that after the end of the pandemic, gradually return to the previous socio-economic activity, on the assumption that market relations in a self-regulating regime will lead to a gradual expansion of practices that have positively proven their effectiveness during a pandemic, for example, remote work or online training. ...

The second is to stimulate the accelerated development of such areas of innovative economic activity, which have shown their resistance to the consequences of quarantine and self-isolation measures, using government regulation and certain planning tools, for example, indicative ones [20-26].

Considering the fact that during the pandemic, the Russian Federation was in the regime of economic sanctions from a number of countries, it can be assumed that even in a more calm economic environment, the issue of lifting them will be long and difficult. Therefore, one of the criteria for efficiency and sustainability should be the country's economic security. At the same time, the methodology for ensuring economic security inherently involves the use of planning principles [27]. Otherwise, there will never be an economically safe economy in Russia only due to market self-regulation. And here, in our opinion, it is most expedient to use the indicative planning toolkit, which contributes to the achievement of an acceptable level of economic security in a relatively short period of time, as well as its maintenance at the required level.

In the context of this study, it is also advisable to answer the question "What fundamental long-term consequences can the COVID-19 coronavirus pandemic lead to?" There will be many consequences, but the following are the main ones.

Firstly, the accelerated innovative digitalization of all socio-economic processes. For many business representatives, the pandemic will create a need for or remove restrictions on the widespread use of digital technologies in production processes. Here we can highlight remote work and robotization. It is necessary to create and develop domestic digital platforms used, for example, in online training or intra-corporate communication. This is a very broad topic, therefore, within the framework of this article, we have only 
fixed this main direction of innovative development or transformation of many countries, incl. and Russia.

The second innovative consequence of the pandemic can be conditionally formulated as "zeroing" the working person. If the black plague epidemic in medieval Europe raised the value of a person as a production unit, then the COVID-19 coronavirus pandemic will stimulate the activation of the processes of ousting a person from various production and service processes.

\section{Conclusion}

In conclusion, the following main conclusions can be drawn. First, the COVID-19 coronavirus pandemic from the point of view of socio-economic processes has shown a high degree of vulnerability of humanity and the world economy to negative external factors.

Secondly, almost all countries reacted very harshly, which was caused by the following main factors: information openness and interpenetration of the world community, developed air traffic between countries and within countries, health systems of many countries, built mainly on market principles, were not able to function effectively in crisis situations.

Thirdly, the consequences of the pandemic are the global economic downturn, which has an "anti-globalization" nature, in which the greatest recession is observed in the industries that moved people and goods between countries and sold the latter. Within countries, offline small and medium-sized B2C businesses have suffered significantly.

Fourth, enterprises that were severely affected during the pandemic cannot count on a quick recovery in demand after the end of the pandemic, maintaining or increasing sales volumes - an increase in the share of their goods or services as part of consumer spending.

Fifth, the main fundamental consequences of the COVID-19 coronavirus pandemic may be two interrelated innovation processes: accelerating digitalization of all aspects of socioeconomic activity, as well as "zeroing", i.e. gradual displacement of a person from many processes where he carried out labor activities.

Sixth, in the process of studying the causes, consequences and necessary actions to overcome the negative consequences of the COVID-19 coronavirus pandemic, their relationship with the problem of ensuring the country's innovative development using indicative planning tools was substantiated, which is the subject of further research.

\section{Acknowledgements}

The work was prepared with the financial support of the RFBR in the framework of the scientific project No. 18-010-00459.

\section{References}

1. Nassim Taleb called the dangerous consequences of the coronavirus, https://www.rbc.ru/society/21/04/2020/5e9de2fc9a794709343c7ec9

2. Taleb Says 'White Swan' Coronavirus Was Preventable, https://www.bloomberg.com/news/videos/2020-03-31/nassim-taleb-says-white-swancoronavirus-pandemic-was-preventable-video

3. A. Schumpeter, The Theory of Economic Development: An Inquiry into Profits, Capital, Credit, Interest and the Business Cycle, translated from the German by 
Redvers Opie (New Brunswick (USA) and London (UK), Transaction Publishers, 1983)

4. P.F. Drucker, Market: how to become leaders: practice and principles (Moscow, 1992)

5. P.F. Druker, Innovation and Entrepreneurship: Practice and Principles (Harper \& Row, 1986)

6. A. Prigogine, G. Nicolis, Self-Organization in Non-Equilibrium Systems (Wiley, 1977)

7. F. Janszen, The Age of Innovation: Making business Creativity a Competence, Not a Coincidence (Financial Times Prentice Hall, 2000)

8. E.V. Balatsky, Terra Economicus 17(2), 6 (2019)

9. Doing Business 2020. Comparing Business Regulation in 190 Economies. World Bank Group,

https://openknowledge.worldbank.org/bitstream/handle/10986/32436/9781464814402. pdf

10. The Global Innovation Index 2019: Creating Healthy Lives - The Future of Medical Innovation, https://www.globalinnovationindex.org/Home

11. Global Competitiveness Report 2019. World Economic Forum, http://www3.weforum.org/docs/WEF_TheGlobalCompetitivenessReport2019.pdf

12. Order of the Government of the Russian Federation No. 2227-r dated 8.12.2011 "Strategy for the innovative development of the Russian Federation for the period until 2020", https://digital.gov.ru/common/upload/2227-pril.pdf

13. Decree of the President of the Russian Federation "On the strategy of scientific and technological development of the Russian Federation", http://static.kremlin.ru/media/events/files/ru/uZiATIOJiq5tZsJgqcZLY9YyL8PWTXQ b.pdf

14. Statement by the Director-General of WHO at the meeting of the Executive Office of the Cities anited and Local Authorities, https://www.who.int/ru/dg/speeches/detail/who-director-general-s-remarks-at-theexecutive-bureau-of-the-united-cities-and-local-governments

15. A.I. Ladykova, Bulletin of Economics, Law and Sociology 2, 40 (2018)

16. The Global Risk Report (2020) https://www.weforum.org/reports/the-global-risksreport-2020

17. G. Gopinat, Great self-isolation: the deepest economic recession since the Great Depression, Blog of the IMF https://www.imf.org/ru/News/Articles/2020/04/14/blog-weo-the-great-lockdownworst-economic-downturn-since-the-great- depression

18. Plan for overcoming the economic consequences of the new coronavirus infection as of 04.20.2020. The Government of the Russian Federation, https://www.economy.gov.ru/material/file/2f659644fd6967df378c8267f22ba839/Plan. pdf

19. Russian Railways increase the volume of export deliveries through seaports, https://expert.ru/2020/04/27/rzhd-naraschivayut-ob_emyi-eksportnyih-postavokcherez-morskie-portyi/

20. V. Krolivetskaya, E. Krolivetsky, E3S Web Conf. 135, 05026 (2019) DOI: https://doi.org/10.1051/e3sconf/201913504032.

21. A. Evmenov, E. Krolivetsky, S. Krolivetskaya, T. Sorvina, E3S Web Conf. 164, 10036 (2020) DOI: https://doi.org/10.17323/j.jcfr.2073-0438.13.2.2019.104-113 
22. D.A. Radushinsky, A. Radushinskaya, I. Radikov et al., MATEC Web of Conferences 170, 01043 (2018) DOI: https://doi.org/10.1051/matecconf/201817001043

23. D. Radoushinsky, E. Markovskaya, V. Holodkova, Journal of Corporate Finance Research 13(2), $104 \quad$ (2019) DOI: https://doi.org/10.17323/j.jcfr.20730438.13.2.2019.104-113

24. D. Radoushinsky, E. Markovskaya, V. Holodkova et al., MATEC Web of Conferences 170, 01047 (2018) DOI https://doi.org/10.1051/ matecconf/201817001047

25. N.I. Evmenova, E.N. Krolivetskiy, St. Petersburg Economic Journal 1, 15 (2020)

26. E.N. Krolivetskiy, O.A. Sorokin, Bulletin of Education and Science Development of the Russian Academy of Natural Sciences 3, 20 (2017)

27. I.P. Danilov, S.Yu. Mikhailova, Oeconomia et Jus 3, 10 (2016) 